\title{
Generation of Circularly Permuted Fluorescent-Protein- Based Indicators for In Vitro and In Vivo Detection of Citrate
}

\author{
Yuki Honda, Kohtaro Kirimura* \\ Department of Applied Chemistry, Faculty of Science and Engineering, Waseda University, Tokyo, Japan
}

\begin{abstract}
Indicators for citrate, particularly those applicable to its in vivo detection and quantitation, have attracted much interest in both biochemical studies and industrial applications since citrate is a key metabolic intermediate playing important roles in living cells. We generated novel fluorescence indicators for citrate by fusing the circularly permuted fluorescent protein (cpFP) and the periplasmic domain of the bacterial histidine kinase CitA, which can bind to citrate with high specificity. The ratiometric fluorescent signal change was observed with one of these cpFP-based indicators, named CF98: upon addition of citrate, the excitation peak at $504 \mathrm{~nm}$ increased proportionally to the decrease in the peak at $413 \mathrm{~nm}$, suitable for build-in quantitative estimation of the binding compound. We confirmed that CF98 can be used for detecting citrate in vitro at millimolar levels in the range of 0.1 to $50 \mathrm{mM}$ with high selectivity; even in the presence of other organic acids such as isocitrate and malate, the fluorescence intensity of CF98 remains unaffected. We finally demonstrated the in vivo applicability of CF98 to estimation of the intracellular citrate concentration in Escherichia coli co-expressing the genes encoding CF98 and the citrate carrier CitT. The novel indicator CF98 can be a specific and simple detection tool for citrate in vitro and a non-invasive tool for real-time estimation of intracellular concentrations of the compound in vivo.
\end{abstract}

Citation: Honda Y, Kirimura K (2013) Generation of Circularly Permuted Fluorescent-Protein-Based Indicators for In Vitro and In Vivo Detection of Citrate. PLoS ONE 8(5): e64597. doi:10.1371/journal.pone.0064597

Editor: Pratul K. Agarwal, Oak Ridge National Laboratory, United States of America

Received February 13, 2013; Accepted April 15, 2013; Published May 22, 2013

Copyright: (C) 2013 Honda and Kirimura. This is an open-access article distributed under the terms of the Creative Commons Attribution License, which permits unrestricted use, distribution, and reproduction in any medium, provided the original author and source are credited.

Funding: This work was partly supported by the grants from Mizuho Foundation for the Promotion of Sciences (Japan). No additional external funding received for this study. The funder had no role in study design, data collection and analysis, decision to publish, or preparation of the manuscript.

Competing Interests: The authors have declared that no competing interests exist.

*E-mail: kkohtaro@waseda.jp

\section{Introduction}

Citrate is a key metabolic intermediate playing important roles in living cells since it is the biomolecule located at the starting point of the tricarboxylic acid (TCA) cycle, also called citric acid cycle [1]. It is also of industrial importance: it has been used for a long time as an acidulant in the manufacture of soft drinks and in the confectionery industry, as a complexing agent in metal treatment, as a monomer for functional and/or biodegradable polymers, and as a water softener in detergents, on the basis of its multimodal properties as an organic acid, chelating agent, and buffering substance [2]. Commercial production of citrate is based on fermentation using the filamentous fungus Aspergillus niger and the global production of citrate has increased to approximately $1,750,000$ tons in 2011 [3]. The mechanism and machinery of citric acid fermentation by $A$. niger has been studied from the viewpoints of bioscience and biotechnology [2]. In biochemistry, citrate is not only a molecule involved in catabolic processes but also a biosynthetic precursor that exhibits regulatory functions for fatty acid synthesis [4]. In addition, since estimation of citrate concentration in urine is of considerable value in diagnosis of certain diseases, such as kidney stones [5] and prostate cancer [6], qualitative and quantitative analysis of citrate is also of importance in medical field. Hence, indicators applicable to both simple and rapid in vitro and in vivo detection of citrate have attracted much interest in basic as wells as applied researches.
A number of genetically encoded fluorescent indicators for in vivo metabolites have been developed from green fluorescent protein (GFP) and its variants (reviewed in [7]). We also have adopted the visual analysis method using fluorescent protein in studies of citrate production by $A$. niger $[8,9,10]$. The major approach to generating these genetically encoded fluorescent indicators is based on fluorescence resonance energy transfer (FRET), and so far many FRET-based indicators for metabolites have been developed (reviewed in [11], e.g., for cAMP [12], ATP [13], glutamate [14], maltose [15], glucose [16], and citrate [17]). On the other hand, some genetically encoded fluorescent indicators employ an alternative approach based on circularly permuted fluorescent proteins (cpFPs), in which the original $\mathrm{N}$ and $\mathrm{C}$ termini are connected via a peptide linker, and new $\mathrm{N}$ and $\mathrm{C}$ termini are created in close proximity to the chromophore [18]. Circularly permutation thus allows placing the fusion of a sensor domain in close proximity to the chromophore environment, which can lead to direct changes in the fluorescence signal upon structural rearrangements initiated by the sensor domain. The calcium indicator Pericam [19], the hydrogen peroxide indicator HyPer [20,21], and the ATP:ADP ratio indicator Perceval [22] have been generated by fusing the $\mathrm{N}$ and $\mathrm{C}$ termini of a cpFP to a specific detector protein for $\mathrm{Ca}^{2+}$, hydrogen peroxide, and ATP/ $\mathrm{ADP}$, respectively. Conformational changes of fusion proteins caused by the binding of the intended compounds to the detector protein domain lead to fluorescence changes. Therefore, the cpFP 
system provides us with novel non-invasive fluorescent indicators useful for qualitative and quantitative detection of the binding compounds as well as imaging of localization and dynamics of the fusion proteins. However, to our knowledge, so far there have been no reports concerning cpFP-based indicators for organic acids, including citrate.

In this study, for the first time, we generated a series of novel citrate indicators in which each of the cpFP mutants tested was inserted into the region of Klebsiella pneumoniae CitA protein, a highly specific citrate receptor $[23,24,25,26,27,28]$, that would undergo great conformational changes upon binding to citrate, examined their properties, and selected the best candidate for the simple and rapid in vitro analysis of citrate. Here, we report the molecular and physicochemical properties of the newly generated cpFP-based indicator for citrate and demonstrate its high selectivity against the compound among various organic acids. Finally, its applicability to estimation of in vivo citrate concentration in Escherichia coli was clearly shown, and the methodology to correct for the intracellular $\mathrm{pH}$ effects on its fluorescence signal was developed based on the ratiometric property observed in the excitation spectra of the indicator protein.

\section{Results}

\section{Generation of cpFP-based indicators for citrate}

To generate a cpFP-based indicator for citrate, we chose the periplasmic domain of the sensor histidine kinase CitA from $K$. pneumoniae $[23,24,25,26,27,28]$ as a suitable citrate-binding detector protein on the basis of the following findings: 1) citrate binds to the recombinant sensor domain of CitA (CitAP; corresponding to
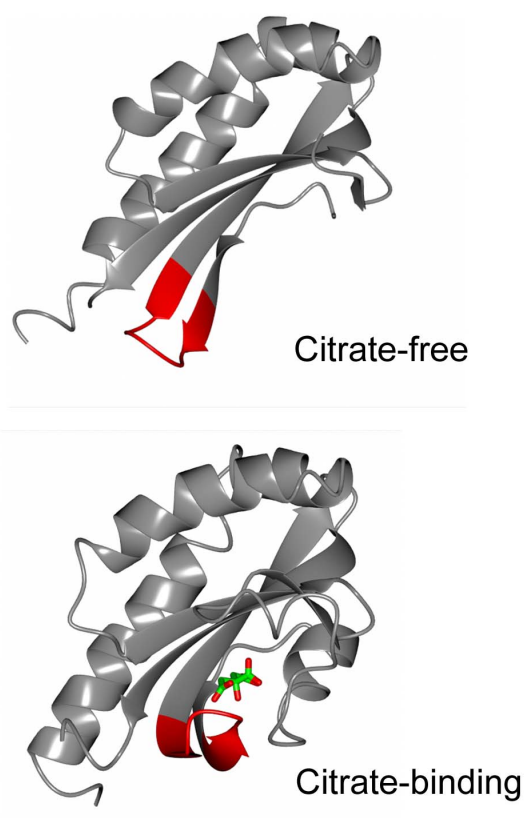

Figure 1. Conformational change of CitAP upon citrate binding. Ribbon representations of citrate-free (2V9A) and citratebinding (2J80) structures of the periplasmic domain of sensor histidine kinase CitA (CitAP, residues 45-176) are drawn using moleculargraphics software, CCP4mg, based on Protein Data Bank files. Citrate is indicated in stick form (green and red). The red colored ribbon parts (residues 97-105) represent the flexible and target region for the insertion of a circularly permuted fluorescent protein to generate the fluorescent-protein-based indicators for citrate.

doi:10.1371/journal.pone.0064597.g001 residues 45-176 of CitA) with high specificity [25,26], and 2) citrate binding to CitAP results in a dramatic conformational change demonstrated by X-ray and NMR analyses [28], as shown in Figure 1. These ribbon representation of citrate-free and citratebinding structures of CitAP are drawn using molecular-graphics software CCP4mg [29] based on Protein Data Bank files (citrate free, 2V9A; citrate binding, 2J80). CitA regulates several citrate metabolism genes under anoxic conditions in the presence of environmental citrate in $K$. pneumoniae [23,24,25]. Citrate binding to the periplasmic domain of CitA constitutes the trigger for subsequent transmembrane signaling events. In addition, CitA was used as sensor domain of a previously reported FRET-based citrate indicator [17].

In CitAP, the flexible region allowing the insertion of cpFP moiety is located at residues 97-105 (locations of the amino acid residues of CitAP correspond to those of CitA in this paper) according to its structural data [28]. We generated nine chimeric proteins by inserting cpFP into the flexible region of CitAP. The resultant chimeric proteins have the following structures: CitA residues $45-\mathcal{N}$-SAG-cpFP-GT-CitAP residues $(\mathcal{N}+1)-176-\mathrm{His}_{6}$, where $\mathcal{N}$ is the location number of any one of CitA residues between 97 and 105, and SAG and GT are short amino acid linkers between CitAP and cpFP. These nine chimeric proteins named CF97 to CF105 according to the location number $\mathcal{N}$ were produced with a hexa-histidine tag (His tag) at $\mathrm{C}$ termini using $E$. coli $\mathrm{BL} 21(\mathrm{DE} 3)$, and purified by $\mathrm{Ni}^{2+}$-affinity chromatography. All of these proteins were confirmed to have a predicted molecular weight of $43.0 \mathrm{kDa}$ by SDS-PAGE. Chimeric proteins CF97, CF98, CF99, GF100, GF101, GF102, and CF103 were obtained in high yields (>1.0 mg-protein/ml), while CF104 and CF105 in low yields $(<10 \mu$ g-protein $/ \mathrm{ml})$.

In the excitation spectral analysis measuring fluorescence emitted at $525 \mathrm{~nm}$, all but CF104 (with a prominent peak at $413 \mathrm{~nm}$ ) showed a prominent fluorescence peak at approximately $504 \mathrm{~nm}$ of excitation wavelength with a smaller peak at approximately $413 \mathrm{~nm}$ (Figure 2). To confirm the citrate concentration-dependence of the fluorescence signal, the excitation spectra of the nine chimeric proteins were measured in a buffer containing $0.05,0.5,5,50$, and $100 \mathrm{mM}$ citrate. The fluorescence intensities that were excited at $504 \mathrm{~nm}$ (FI504) and emitted at $525 \mathrm{~nm}$ by CF97, CF99, CF100, CF102, CF103, GF104, and CF105 decreased upon citrate addition. Among these seven chimeric proteins, CF99 showed the highest fluorescence intensity. In contrast, FI504 by CF98 and CF101 increased upon citrate addition: the former showed higher fluorescence intensity. On the other hand, no such fluorescence signal changes were caused by the reaction of any of the cpFPs with $200 \mathrm{mM} \mathrm{NaCl}$. In parallel experiments, to examine whether or not the smaller peak found at approximately $413 \mathrm{~nm}$ in the spectra was due to the fluorescence signal from cpFP, the excitation spectra of CF98 and CF99 were remeasured at $540 \mathrm{~nm}$ of emission wavelength instead of $525 \mathrm{~nm}$. Despite such a change in emission wavelength, the peak at approximately $413 \mathrm{~nm}$ still appeared in the excitation spectra of CF98 and CF99 (data not shown). These results suggest that the small peak at $413 \mathrm{~nm}$ may not be attributed to other spectroscopic phenomena, e.g., Raman scattering, but to the fluorescence signal from CF98 and CF99.

We focused on CF98 as the cpFP-based citrate indicator for the analyses of the molecular and physicochemical properties because of the high fluorescence intensity, its clear citrate-concentration dependence, and its ideal detectable range for the intracellular citrate concentration. 

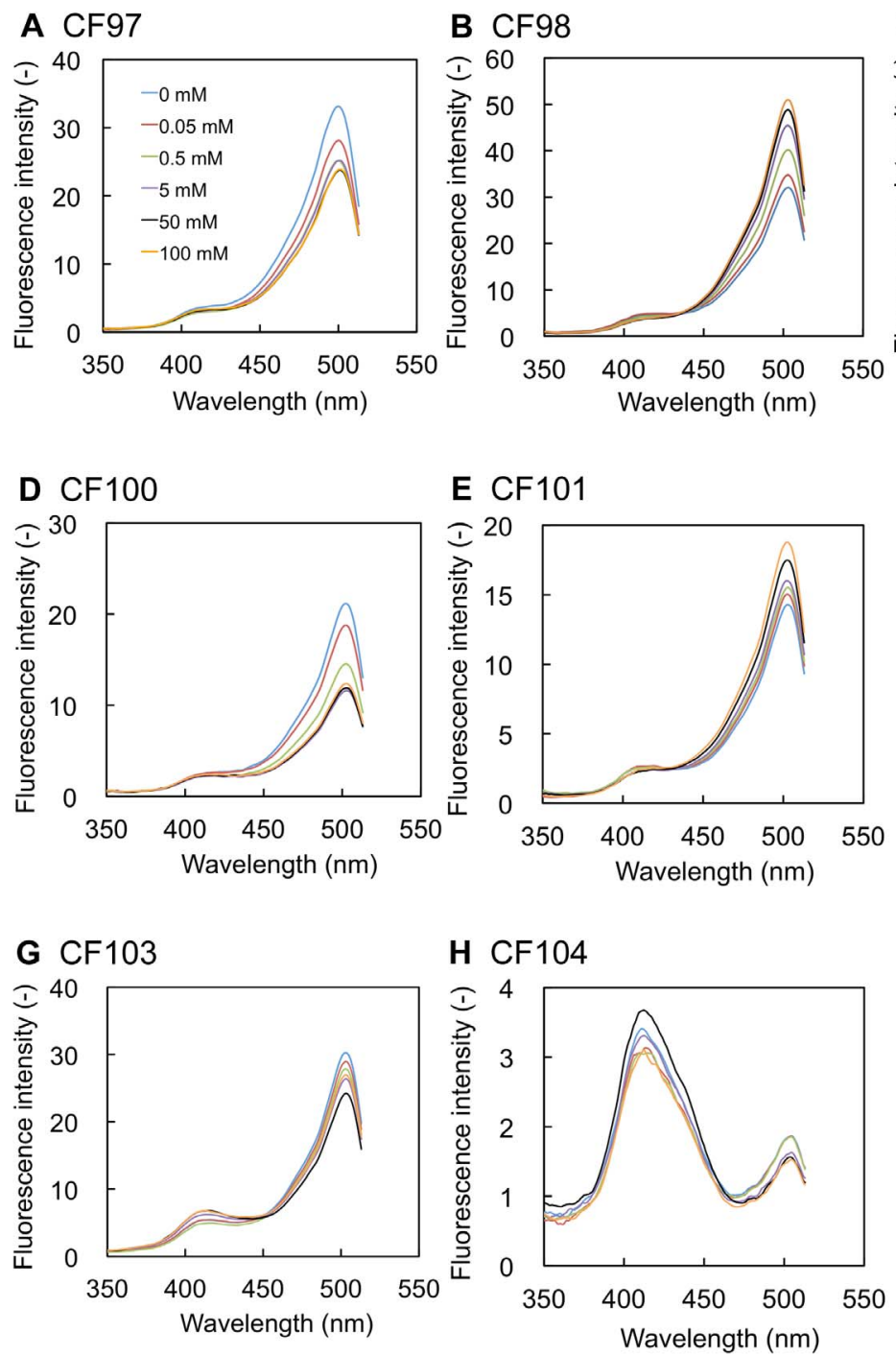
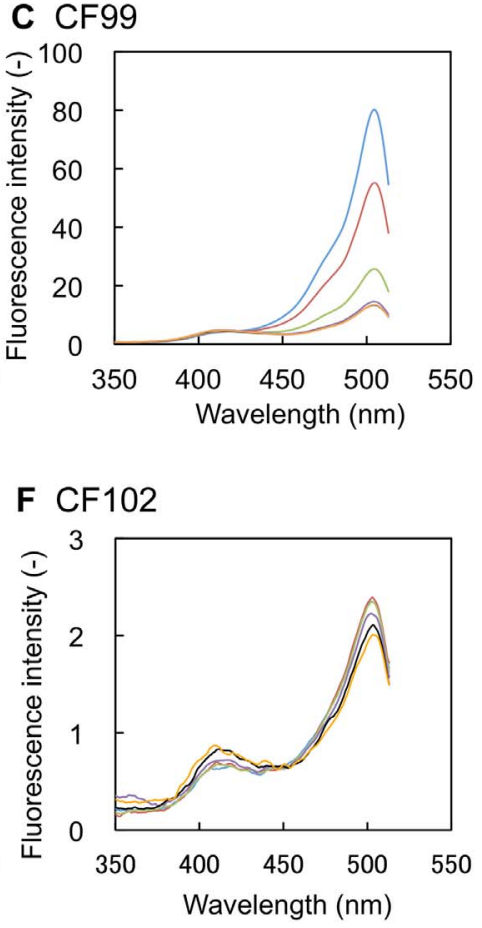

I CF105

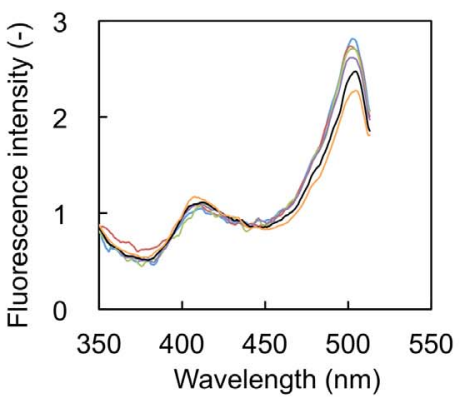

Figure 2. Excitation spectra of nine chimeric proteins, CF97-CF105. Nine chimeric proteins were produced and purified as described in Materials and Methods. The excitation spectra of these chimeric proteins were measured upon the addition of the indicated citrate concentrations. The concentrations of the chimeric protein solutions of CF97, CF98, CF99, CF100, CF101, CF102, and CF103 were adjusted to 20 $\mu$ g-protein/ml by $50 \mathrm{mM} \mathrm{Na}{ }_{2} \mathrm{HPO}_{4}-\mathrm{NaH}_{2} \mathrm{PO}_{4}$ buffer ( $\mathrm{pH} 7.0$ ), respectively, and those of CF104 and CF105 were adjusted to the value of 6.8 and $3.6 \mu \mathrm{g}-\mathrm{protein} / \mathrm{ml}$ by adding $50 \mathrm{mM} \mathrm{Na} \mathrm{HPO}_{4}-\mathrm{NaH}_{2} \mathrm{PO}_{4}$ buffer ( $\mathrm{pH} 7.0$ ), respectively. Emission at $525 \mathrm{~nm}$.

doi:10.1371/journal.pone.0064597.g002

\section{In Vitro characterization of CF98}

The fluorescence changes of CF98 were rapidly observed $(<1 \mathrm{msec})$ upon the addition of citrate in the range of 0.1 to $50 \mathrm{mM}$. The dependence of CF98 excitation and fluorescence emission was further tested by mixing of purified CF98 $(3.0 \mathrm{mg}$ protein $/ \mathrm{ml}$ ) with different concentrations of citrate (Figure $3 \mathrm{~A}$ ). Increase in the fluorescence intensities of CF98 was shown to be apparently proportional to the increasing concentrations of citrate in the range of 0.1 to $50 \mathrm{mM}$.

The excitation spectra of CF98 (emission at $525 \mathrm{~nm}$ ) showed a prominent peak at $504 \mathrm{~nm}$ with a minor one at $413 \mathrm{~nm}$ (Figure 3B) and the emission spectra of CF98 (excitation at $475 \mathrm{~nm}$ ) showed a peak at $518 \mathrm{~nm}$ (Figure 3C). As shown in Figure 3B, the major $504 \mathrm{~nm}$ peak was markedly enhanced, while the minor $413 \mathrm{~nm}$ peak was almost disappeared, as citrate concentrations increased, implying that the increase of citrate concentration leads to a ratiometric change in the excitation spectrum of CF98. The FI ratios (FI504/FI413) of GF98 were increased by the addition of increasing amounts of citrate (Figure 3D), but they were independent of protein concentrations of CF98 (data not shown). Thus, measuring the ratio of the fluorescence intensities of the peaks between at $413 \mathrm{~nm}$ and at $504 \mathrm{~nm}$ allows us to estimate the citrate concentrations independently of those of the fluorescent protein.

To examine the selectivity of CF98 toward citrate, we tested the effects of several organic acids on the excitation spectra of CF98 (Table 1). The fluorescence intensities of CF98 changed only upon the addition of $5 \mathrm{mM}$ citrate and none of the other carboxylates ( $5 \mathrm{mM}$ each) tested were able to induce any significant changes in the FI504/FI413 ratio of the fluorescence emitted at $525 \mathrm{~nm}$. Table 1 also clearly indicates that GF98 can detect citrate even in the buffer containing other organic acids, such as isocitrate and malate. These findings strongly suggest that CF98 may be valuable for highly selective assay of citrate. The fluorescence intensities (excitation at $504 \mathrm{~nm}$ and emission at $525 \mathrm{~nm}$ ) of CF98 were 
A

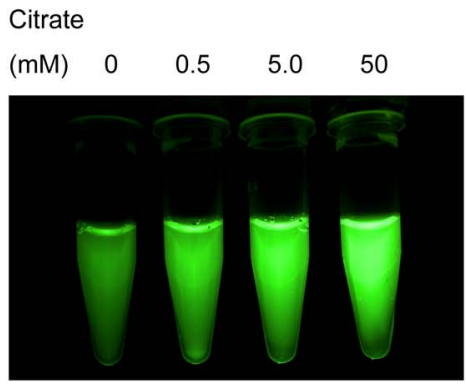

C

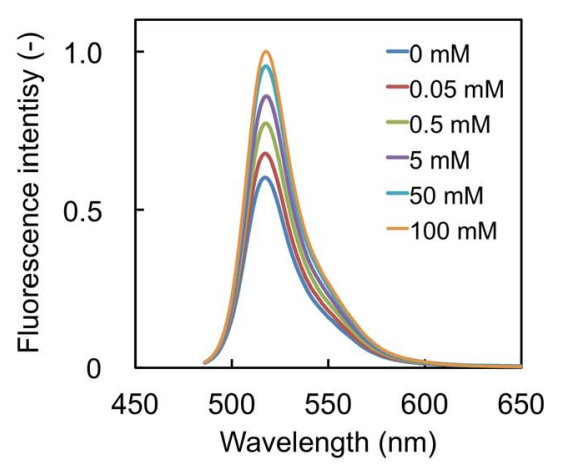

B

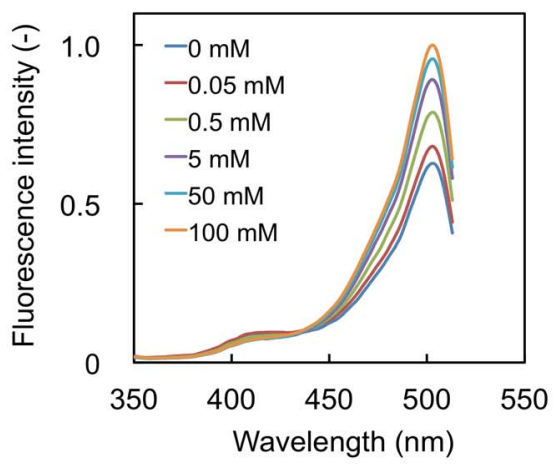

D

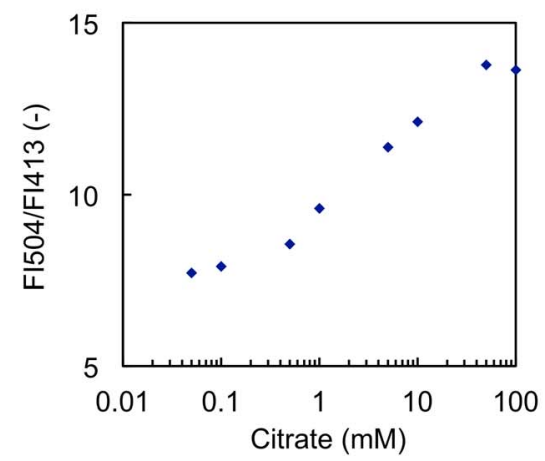

Figure 3. Fluorescence properties of CF98. A, Photoimages of CF98. Purified CF98 (3.0 mg-protein/ml) in 50 mM Na $\mathrm{HPO}_{4}-\mathrm{NaH}_{2} \mathrm{PO}_{4}$ buffer (pH 7.0) containing the indicated citrate concentration was poured into $0.6-\mathrm{ml}$ microtubes. The microtubes were then illuminated with $470 \mathrm{~nm}$ LED light for excitation, and photos were taken with a digital camera using a long-pass filter of $515 \mathrm{~nm}$ to exclude $470 \mathrm{~nm}$ LED light in a darkroom with constant exposure. B, Excitation spectra of CF98. Excitation spectra (emission at $525 \mathrm{~nm}$ ) of CF98 were measured in $50 \mathrm{mM} \mathrm{Na}_{2} \mathrm{HPO}_{4}-\mathrm{NaH}_{2} \mathrm{PO}_{4}$ buffer (pH 7.0) containing the indicated citrate concentration. C, Emission spectra of CF98. Emission spectra (excitation at $475 \mathrm{~nm}$ ) of CF98 were measured in $50 \mathrm{mM} \mathrm{Na} 2 \mathrm{HPO}_{4}-\mathrm{NaH}_{2} \mathrm{PO}_{4}$ buffer (pH 7.0) containing the indicated citrate concentration. D, Fluorescence intensity ratio of CF98. The ratio of the fluorescence intensity at $504 \mathrm{~nm}$ (FI504) to that at $413 \mathrm{~nm}$ (FI413) was plotted against citrate concentration. Data points are averages of three independent experiments. Error bars indicate standard deviations. doi:10.1371/journal.pone.0064597.g003

Table 1. Citrate-selective fluorescent property of CF98.

\begin{tabular}{lll}
\hline Carboxylate added & \multicolumn{2}{l}{ FI/504/F1413 of CF98 } \\
\cline { 2 - 3 } & Citrate $\mathbf{0 ~} \mathbf{~ m M}$ & $\mathbf{5} \mathbf{~ m M}$ \\
\hline None & $7.13 \pm 0.195$ & $12.0 \pm 0.523$ \\
Isocitrate & $7.55 \pm 0.416$ & $12.2 \pm 0.597$ \\
$\alpha$-Ketoglutarate & $6.90 \pm 0.175$ & $12.2 \pm 0.364$ \\
Succinate & $7.19 \pm 0.104$ & $12.1 \pm 0.315$ \\
Fumarate & $7.02 \pm 0.248$ & $12.3 \pm 0.701$ \\
Malate & $6.96 \pm 0.123$ & $12.5 \pm 0.771$ \\
Oxaloacetate & $6.69 \pm 0.309$ & $12.0 \pm 0.477$ \\
Pyruvate & $7.22 \pm 0.383$ & $12.0 \pm 0.521$ \\
\hline
\end{tabular}

Fluorescence intensities (Fls) by purified recombinant CF98 protein were measured at $525 \mathrm{~nm}$ when excited at $504 \mathrm{~nm}$ (FI504) and $413 \mathrm{~nm}$ (FI413) in $50 \mathrm{mM} \mathrm{Na} 2 \mathrm{HPO}_{4}-\mathrm{NaH}_{2} \mathrm{PO}_{4}$ buffer ( $\mathrm{pH}$ 7.0) containing the indicated carboxylates $(5 \mathrm{mM})$. The values are averages and standard deviations of three independent experiments.

doi:10.1371/journal.pone.0064597.t001 found to be sensitive to $\mathrm{pH}$ and metal ions (Figure $\mathrm{S} 1$ and Table S2, respectively) by measuring the excitation spectra of CF98 using a series of buffers ( $\mathrm{pH} 6.5$ to $\mathrm{pH} 8.0$ ) containing each of various metal ions. These data will be of use in the formulation of the conditions of citrate assay with this specific fluorescent protein.

\section{In vivo assay of citrate concentrations in E. coli}

Using E. coli cells expressing the gene encoding the citrate carrier protein CitT [30], we tested the capability of CF98 to detect the in vivo changes of citrate concentrations. Since CitT of $E$. coli is a transporter exchanging extracellular citrate and intracellular carboxylate, it is presumed that the change in the extracellular citrate concentration would rapidly cause changes in the intracellular citrate concentration of $E$. coli cells expressing the gene encoding GitT.

Expression vectors for CF98 and CitT were constructed with pET-21d(+) and pRSFDuet-1, named pECF98 and pRCITT, respectively, and then used for co-transformation of E.coli BL21(DE3) to obtain E. coli BL21(DE3)/pECF98+pRCITT. E. coli BL21(DE3)/pECF98+pRSFDuet-1, BL21(DE3) carrying pRSFDuet-1 instead of the pRCITT plasmids, was used as a negative control in the in vivo fluorometric analysis. Aliquots of the cell suspension of E. coli BL21(DE3)/pECF98+pRCITT or E. coli 
BL21(DE3)/pECF98+pRSFDuet-1 were poured into a cuvette and placed in a fluorescence spectrometer to start measurement. Buffers containing different citrate concentrations (0 to $2.5 \mathrm{mM}$ ) were added into aliquots of the cell suspension after $50 \mathrm{~s}$ and the changes in fluorescence intensity were sequentially determined.

The time courses of the changes in the fluorescence intensities of CF98 (excitation at $504 \mathrm{~nm}$ and emission at $525 \mathrm{~nm}$ ) from aliquots of the cell suspension of E. coli BL21(DE3)/pECF98+pRCITT and E. coli BL21(DE3)/pECF98+pRSFDuet-1 are shown in Figure 4A. The fluorescence intensities of CF98 from aliquots of the cell suspension of $E$. coli BL21(DE3)/pECF98+pRCITT increased with the incremental changes of concentrations of citrate extracellularly added. The fluorescence intensities of CF98 from aliquots of the cell suspension of E. coli BL21(DE3)/pECF98+pRCITT were maximized at $150 \mathrm{~s}$ after the addition of the citrate-

\section{A}

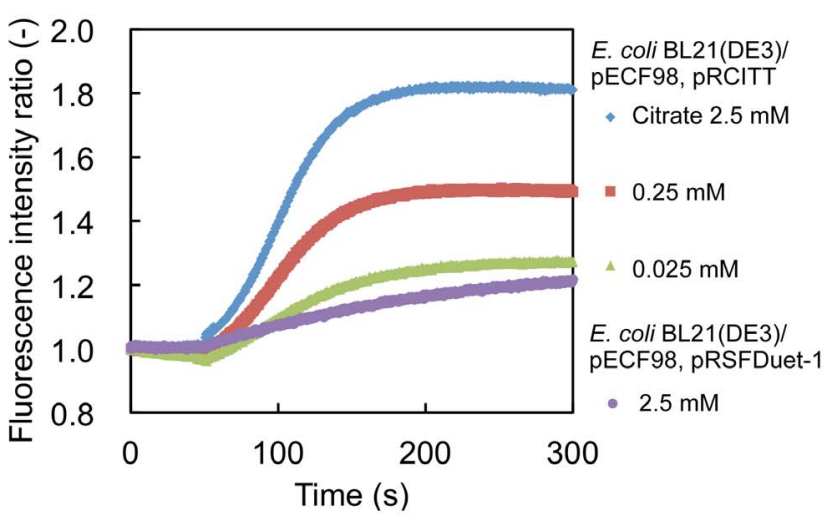

B

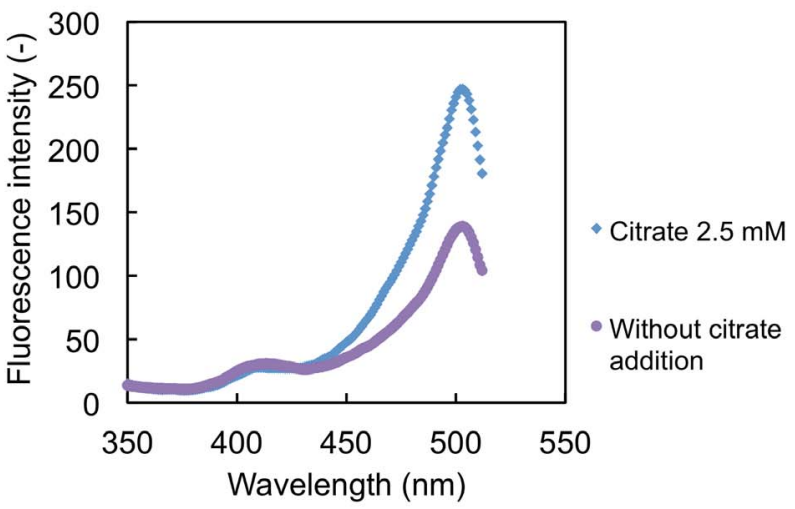

Figure 4. In vivo citrate detection using CF98 in E. coli expressing the gene encoding citrate carrier CitT. A, Time courses of the fluorescence intensities of CF98 from E. coli BL21(DE3)/ pECF98+pRCITT and E. coli BL21(DE3)/pECF98+pRSFDuet-1. The fluorescence intensities of $\mathrm{CF} 98$ from aliquots of the cell suspension were measured in $50 \mathrm{mM} \mathrm{Na} \mathrm{HPO}_{4}-\mathrm{NaH}_{2} \mathrm{PO}_{4}$ buffer (pH 7.0). At $50 \mathrm{~s}$ after starting the measurements, the citrate-containing buffer was added to change the extracellular citrate concentration to the indicated citrate concentrations in the cuvette. The fluorescence intensities (excitation at $504 \mathrm{~nm}$, emission at $525 \mathrm{~nm}$ ) at each time point in three independent experiments were averaged. B, Excitation spectrum (emission at $525 \mathrm{~nm}$ ) of CF98 from aliquots of the cell suspension of $E$. coli BL21(DE3)/pECF98+pRCITT was measured $150 \mathrm{~s}$ after the addition of the citrate-containing buffer to change the citrate concentration from 0 to $2.5 \mathrm{mM}$. The control excitation spectrum was measured without addition of citrate.

doi:10.1371/journal.pone.0064597.g004 containing buffer. The increase in fluorescence intensities was also confirmed in the excitation spectra (Figure 4B). In the excitation spectra of CF98 from aliquots of the cell suspension of $E$. coli BL21(DE3)/pECF98+pRCITT, two peaks at 413 and $504 \mathrm{~nm}$ were detected, the minor $413 \mathrm{~nm}$ peak diminished, and the major $504 \mathrm{~nm}$ peak was enhanced with the citrate addition, analogously to the in vitro analysis with purified CF98, as shown in Figure 3B. In contrast to these results, no significant change in the fluorescence intensities of CF98 with aliquots of the cell suspension of $E$. coli BL21(DE3)/pECF98+pRSFDuet-1 was observed even though the extracellular citrate concentrations changed with the addition of the citrate-containing buffer.

\section{Intracellular pH-dependent change of CF98 fluorescence intensities and its correction}

Since CF98 fluorescence is sensitive in vitro to changes in $\mathrm{pH}$ (Figure S1), it is important for accurate quantitation of citrate to isolate the fluorescence changes induced by the changes in the citrate concentrations from those induced by $\mathrm{pH}$ changes. The intracellular $\mathrm{pH}$ of $E$. coli was determined using the fluorescent $\mathrm{pH}$ indicator dye, SNARF-5F 5-(and-6)-carboxylic acid, acetoxymethyl ester, acetate (SNARF-5F-AM ester; Molecular Probes, OR, USA), in accordance with the manufacturer's protocol. The SNARF-5F signals were calibrated by the high- $\mathrm{K}^{+} /$nigericin method [31].

The excitation spectra (emission at $630 \mathrm{~nm}$ ) of the aliquots of cell suspension of SNARF-5F-loaded $E$. coli BL21(DE3)/ pECF98+pRCITT diluted with each $\mathrm{pH}$ calibration solution showed marked changes in the fluorescence signals of SNARF-5F due to $\mathrm{pH}$ changes (Figure S2). Since the emission peak of CF98 was found at $518 \mathrm{~nm}$ (Figure 3C) and its fluorescence signals hardly overlapped with those of SNARF-5F, the presence of the former in the $E$. coli cells is negligible for determination of the fluorescence emitted from SNARF-5F. The fluorescence spectra of the SNARF-5F-loaded $E$. coli cells showed one excitation peak at $577 \mathrm{~nm}$. A calibration curve for the intracellular $\mathrm{pH}$ of $E$. coli was constructed by plotting the values of the fluorescence intensities excited at $577 \mathrm{~nm}$ and emitted at $630 \mathrm{~nm}$ against the values of $\mathrm{pH}$ (Figure S3).

The excitation spectrum of SNARF-5F from aliquots of the cell suspension of SNARF-5F-loaded E. coli $\mathrm{BL} 21$ (DE3)/pECF98+pRCITT diluted with $50 \mathrm{mM} \mathrm{Na} 2 \mathrm{HPO}_{4}-\mathrm{NaH}_{2} \mathrm{PO}_{4}$ buffer (pH 7.0) and that of the E. coli cell suspension at $150 \mathrm{~s}$ after the addition of the citrate-containing buffer to give a final concentration of $2.5 \mathrm{mM}$ citrate are also shown in Figure S2. The values of $\mathrm{pH}$ inside the $E$. coli cells before and after the citrate addition were barely different ( $\mathrm{pH} 6.59 \pm 0.0608$ and $6.56 \pm 0.0516$, respectively) (Figure S2) based on the calculation with the calibration curve (Figure S3).

The FI504/FI413 ratios of the fluorescence intensities of CF98 allow us to determine the citrate concentrations as shown in Figure 3D. Plotting the FI504/FI413 ratios measured in vitro with purified CF98 against pH enabled us to correct the fluorescence signals of CF98 for $\mathrm{pH}$ (Figure 5). Furthermore, in Figure 5, the FI504/FI413 values of CF98 in the E. coli BL21(DE3)/ pECF98+pRCITT cells before and after citrate addition were calculated from the results shown in Figure 4B and plotted against each of the corresponding intracellular $\mathrm{pH}$ values calculated in Figure S1. The pH-corrected FI504/FI413 values of CF98 in the $E$. coli cells showed a clear increase in response to the elevation of intracellular citrate concentrations, indicating that the newly developed citrate detection system is useful for in vivo as well as in vitro quantitative assay of citrate. 


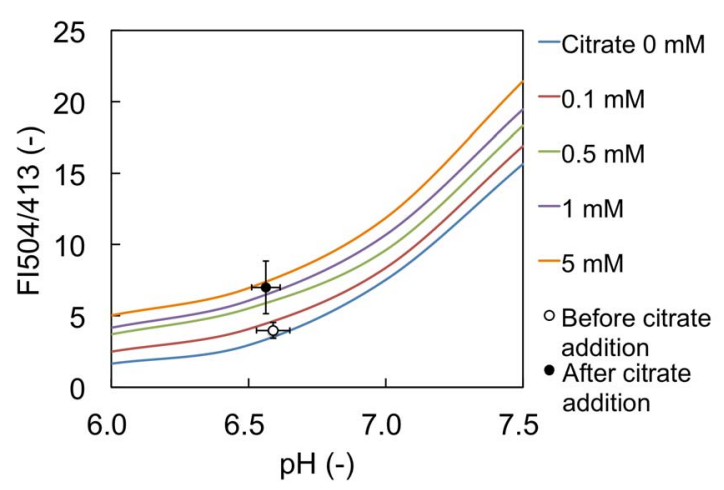

Figure 5. Correction of fluorescence intensities for intracellular pH changes in $E$. coli using SNARF-5F. The ratios of the fluorescence intensities of CF98 (FI504/FI413) were measured using purified CF98 in vitro and are represented by solid lines. The $\mathrm{pH}-$ corrected FI504/FI413 values of CF98 from aliquots of the cell suspension of $E$. coli BL21(DE3)/pECF98+pRCITT before and after citrate addition are also plotted and represented by open and closed circles, respectively. Data points are averages of three independent experiments. Error bars indicate standard deviations.

doi:10.1371/journal.pone.0064597.g005

\section{Discussion}

In this study, we developed the fluorescent-protein-based indicators for citrate by inserting $\mathrm{cpFP}$ in the flexible region of CitAP, the periplasmic domain of a sensor histidine kinase protein CitA that can bind to citrate with high specificity, and examined in detail the molecular and physicochemical properties of CF98 as the most promising citrate indicator. The fluorescent signals of CF98 appeared to be ratiometric: upon citrate addition, the excitation peak at $504 \mathrm{~nm}$ increased proportionally to the decrease in the excitaion peak at $413 \mathrm{~nm}$. The ratiometric properties that also have been reported for ratiometric Pericam [19], Hyper [20], and Perceval [22] are essential for intracellular indicators because they permit built-in normalization of the fluorescence signals irrespective of variations in the concentrations of the indicator proteins. CF98 can detect citrate in the range of 0.1 to $50 \mathrm{mM}$ (Figure 3D) with high selectivity. This detectable range is ideal for the determination of the intracellular citrate concentration in microorganisms, according to the reported data on metabolome analyses $[32,33,34]$. For example, Bennett et al. reported that the intracellular citrate concentration of exponentially growing $E$. coli cells in glucose-fed batch culture is $1.96 \mathrm{mM}$, that of growing with acetate is $2.32 \mathrm{mM}$, and that of growing with acetate is $21.9 \mathrm{mM}$ [33], and that of Saccharomyces cerevisiae cells is determined to be $5.2 \mathrm{mM}[34]$.

We demonstrated the successful application of CF98 to the detection of in vivo changes in citrate concentration by using $E$. coli cells expressing the gene encoding a citrate carrier CitT. Since Cit T functions as a transporter exchanging extracellular citrate and succinate [30], changing the extracellular citrate concentration was predicted to cause changes in the intracellular citrate concentration, in turn leading to the increase in the fluorescence intensities of CF98 in E. coli cells co-expressing the genes encoding CF98 and CitT. As shown in Figure 4, as expected, the fluorescence intensities of CF98 in $E$. coli BL21(DE3)/ pECF98+pRCITT were remarkably increased by the addition of the citrate-containing buffer to the cell suspension, in contrast to no significant change in E. coli BL21(DE3)/pECF98+pRSFDuet-1.

The fluorescence signals of CF98 were found to be sensitive to $\mathrm{pH}$ changes and the existence of some metal ions such as $\mathrm{Fe}^{2+}$ and
$\mathrm{Ni}^{2+}$. Similarly, for all other cpFP-based indicators ever developed, sensitivities of their fluorescence signals to intracellular $\mathrm{pH}$ have imposed problematic technical limitations on their practical uses [19,20,22]. Many metabolic perturbations also affect intracellular $\mathrm{pH}$ and thus these variation factors must be taken into account for the applications of CF98 to in vitro and in vivo of their ligands. We measured the changes in intracellular $\mathrm{pH}$ using the fluorescent $\mathrm{pH}$ indicator dye SNARF-5F and corrected for the $\mathrm{pH}$ effects on CF98 signals by measuring the ratiometric plots of the $\mathrm{pH}$ dependent CF98 fluorescence signals. As a result, the changes in the intracellular citrate concentrations after the addition of citratecontaining buffer to the cell suspension was clearly shown (Figure 5), strongly suggesting that CF98 is an eligible indicator for in vivo as well as in vitro quantitative detection of citrate.

In addition to its wide array of industrial and medical uses, citrate is an important intermediate in TCA cycle and also an essential regulatory molecule in glycolysis and fatty acid synthesis $[4,35]$. Our newly developed cpFP-based citrate indicator can be effectively employed to follow the metabolic activities of cells in question to understand dynamic intracellular events in which citrate is involved in living cells and to explore the mechanism of citrate production.

\section{Materials and Methods}

\section{Strains and cultivation conditions}

E. coli strains JM109 and BL21(DE3) were used as the hosts for the plasmid construction and protein expression, respectively. $K$. pneumoniae NBRC 13541 was used as the source of the gene encoding the sensor histidine kinase CitA. The gene encoding the citrate carrier (CitT: gene ID, 949070) was obtained from the genomic DNA of E. coli W3110 [30]. E. coli and K. pneumoniae strains were grown routinely at $37^{\circ} \mathrm{C}$ in $\mathrm{LB}$ medium with appropriate antibiotics.

\section{Gene expression and protein purification}

Recombinant proteins were produced using E. coli BL21(DE3) as the host and the pET vector system (Novagen), and purified by $\mathrm{Ni}^{2+}$-affinity chromatography using HisTrap HT columns (GE Healthcare). The cell-free extracts were loaded onto HisTrap HT columns that have been equilibrated with TNI5 buffer $(20 \mathrm{mM}$ Tris-HCl, pH 7.9, $500 \mathrm{mM} \mathrm{NaCl}$, and $5 \mathrm{mM}$ imidazole). Weakly binding proteins were removed by washing with five bed volumes of TNI5 buffer. Elution was performed with TNI500 buffer containing $500 \mathrm{mM}$ imidazole and the buffer was subsequently exchanged to $50 \mathrm{mM} \mathrm{Na} 2 \mathrm{HPO}_{4}-\mathrm{NaH}_{2} \mathrm{PO}_{4}$ buffer ( $\mathrm{pH}$ 7.0) by gel filtration with Sephadex G-25 (PD-10 column, GE Healthcare). Protein concentrations were determined by the Bradford method using Coomassie Protein Assay Reagent (Thermo Scientific, Illinois, USA) with bovine serum albumin as the standard.

\section{Construction of CitAP- and cpFP-expression plasmids}

To generate fluorescent-protein-based citrate indicators, the DNA sequence coding for the periplasmic domain of sensor histidine kinase CitA (CitAP) (45-176 residues of CitA) was amplified from the total DNA of $K$. pneumoniae NBRC 13541 by PCR with the specific primers $\operatorname{Pr} 1$ and $\operatorname{Pr} 2$ shown in Table S1. The amplified DNA fragment was digested with $\mathcal{N}_{c o} \mathrm{I}$ and Xho I, and the resulting restriction fragment was inserted into $\mathcal{N}_{c o} \mathrm{I} / X_{h o} \mathrm{I}$ sites of pET-21d(+) vector for construction of the expression plasmid pECitAP.

To generate the cpFPs, two fragments of the enhanced green fluorescent protein (EGFP) coding sequence were amplified from the plasmid pBEGFP-F $[36,37]$ by PCR with the specific primers 
shown in Table S1: Pr3 and Pr4 for the fragment of residues 145238 of EGFP; Pr5 and Pr6 for the fragment of residues 2-144 of EGFP (amino acid residue numbers correspond to those of the standard GFP). The primers Pr3 and Pr6 have short DNA sequences coding for amino acid linkers, -SAG- and -GT-, respectively, located between $\mathrm{cpFP}$ and CitAP, and also have restriction sites, Pst $\mathrm{I}$ and $K p n \mathrm{I}$, respectively. The primers Pr4 and Pr5 have a sequence coding for a linker (-VDGGSGGTGbetween the original $\mathrm{C}$ and $\mathrm{N}$ termini), allowing complementary fragment annealing in the following elongation reactions. These linker sequences (-SAG-, -GT-, and -VDGGSGGTG-) have been optimized for the ratiometric calcium indicator, Pericam [19]. The two fragments amplified with $\operatorname{Pr} 3 / \operatorname{Pr} 4$ and $\operatorname{Pr} 5 / \operatorname{Pr} 6$ were mixed, annealed, and elongated by PCR with $\operatorname{Pr} 3$ and Pr6. The resulting fragment encoding a circularly permuted $\mathrm{cpFP}$ was amplified by PCR with Pr3 and Pr6, digested with Pst I and Kpn I, and the restriction fragment covering the coding region for $\mathrm{cpFP}$ was inserted into pUC19 (Takara Bio). Since the mutation (F46L) was essential for accelerating the chromophore maturation in accordance with the report of the fluorescent protein Venus [38] and the mutations (T65G, V68L, S72A, H148D, T203F) were optimized for the ratiometric Pericam [19], several mutations (F46L, T65G, V68L, S72A, H148D, T203F) were introduced into the cpFP coding sequence by site-directed mutagenesis with primers Pr7-12 (Table S1).

\section{Generation of fluorescent-protein-based indicators for citrate}

To generate fluorescent-protein-based indicators for citrate, the cpFP coding sequence was inserted into the flexible region (between any of the residues 97-105) of the CitAP coding sequence. The chimeric proteins to be obtained have the following structures: CitA residues 45- $N$-SAG-cpFP-GT-CitAP residues $(N+1)-176-\mathrm{His}_{6}$, where $\mathcal{N}$ is the location number of any one of the CitA residues between 97 and 105, and SAG and GT are short amino acid linkers between CitAP and cpFP. To amplify the fragment of the SAG-cpFP-GT coding sequence, the primers Pr13 and Pr14 were used. To amplify the fragment of the CitAP coding sequence, Pr1, Pr2, and Pr15-Pr32 were used. PCR fragments of CitAP residues $45-\mathcal{N}$, SAG-cpFP-GT, and CitAP residues $(\mathcal{N}+1)$ 176 were mixed, and amplified by PCR with $\operatorname{Pr} 1$ and $\operatorname{Pr} 2$. The fragments containing the region encoding the fluorescent-proteinbased indicators for citrate were digested with $\mathcal{N} c o$ I and Xho I, and inserted into pET-21d(+) for the construction of the CitAP and cpFP expression plasmids (pECF97 to pECF105) that were used for transformation of $E$. coli BL21(DE3) to produce the chimeric proteins. The chimeric proteins were named CF97 to CF105 according to the location number $\mathcal{N}$. The full nucleotide and protein sequences of CF98 are given in Figure S4.

\section{Fluorometric analysis}

Chimeric proteins were purified as His-tagged proteins from the recombinant $E$. coli BL21(DE3) cells expressing each of the chimeric proteins. The fluorescence spectra of the purified chimeric proteins were measured in $50 \mathrm{mM} \mathrm{Na} \mathrm{HPO}_{4}-\mathrm{NaH}_{2} \mathrm{PO}_{4}$ buffer ( $\mathrm{pH}$ 7.0) (control) supplemented with or without citrate using a fluorescence spectrometer (FP-6200, JASCO Corporation) that was equipped with a water thermostated cell holder with a stirrer (STR-312, JASCO Corporation) and a sample holder lid with a syringe port (CSP-622, JASCO Corporation). Excitation spectra were measured at $25^{\circ} \mathrm{C}$ by the spectrometer under the following conditions: emission wavelength, $525 \mathrm{~nm}$; wavelength range, 350-512 nm; spectral bandwidth, $5 \mathrm{~nm}$; response, medium; wavelength scan speed, $2000 \mathrm{~nm} / \mathrm{min}$; gain, medium.
Emission spectra were measured under the following conditions: excitation wavelength, $475 \mathrm{~nm}$; wavelength range, 482-650 nm; spectral bandwidth, $5 \mathrm{~nm}$; response, medium; wavelength scan speed, $2000 \mathrm{~nm} / \mathrm{min}$; gain, medium.

\section{In vivo assay of citrate concentration in E. coli}

To express the gene encoding CF98 in the in vivo assay of the changes in the intracellular citrate concentration, $E$. coli BL21(DE3) cells carrying pECF98 and pRCITT or pRSFDuet-1 (Novagen) as the negative control were used. To express the genes encoding CF98 and CitT, E. coli BL21(DE3)/pECF98+pRCITT cells were cultivated and the culture of E. coli BL21(DE3)/ pECF98+pRSFDuet-1 was used as the control. After the induction of the genes, $E$. coli cells were harvested by centrifugation, washed twice with $50 \mathrm{mM} \mathrm{Na} \mathrm{HPO}_{4}-\mathrm{NaH}_{2} \mathrm{PO}_{4}$ buffer (pH 7.0), and resuspended in the same buffer. Aliquots of the $E$. coli cell suspension were used for the detection of the changes in the intracellular citrate concentration and the intracellular $\mathrm{pH}$ calibration.

The plasmid pRCITT, an expression vector of the gene encoding citrate carrier (CitT; Gene ID, 949070) in E. coli K-12 [30], was constructed as follows. A fragment of the gene encoding CitT was amplified from the total DNA extracted from E. coli W31 10 by PCR with the specific primers Pr33 and Pr34, shown in Table $\mathrm{S} 1$, and the amplified fragment was digested with $\mathcal{N} d e \mathrm{I}$ and $M f e \mathrm{I}$. The resulting restriction fragment was inserted into the $\mathcal{N} d e$ I/Mfe I sites of pRSFDuet-1 (Novagen) for the construction of the plasmid pRCITT. Aliquots of the cell suspension of $E$. coli BL21(DE3)/pECF98+pRCITT and E. coli BL21(DE3)/ pECF98+pRSFDuet-1 (negative control) were applied to the fluorometric analysis. To measure the changes in the fluorescence intensities of CF98 due to the changes in the intracellular citrate concentration, $100 \mu \mathrm{l}$ of the cell suspension and $1,875 \mu \mathrm{l}$ of $50 \mathrm{mM} \mathrm{Na} 2 \mathrm{HPO}_{4}-\mathrm{NaH}_{2} \mathrm{PO}_{4}$ buffer $(\mathrm{pH}$ 7.0) were poured into a cuvette and placed in the spectrometer. During the measurement of the fluorescence intensities, $25 \mu \mathrm{l}$ of $200 \mathrm{mM}$ citrate-containing $50 \mathrm{mM} \mathrm{Na} 2 \mathrm{HPO}_{4}-\mathrm{NaH}_{2} \mathrm{PO}_{4}$ buffer ( $\mathrm{pH}$ 7.0) were added to the aliquots of the cell suspension.

\section{Intracellular $\mathrm{pH}$ calibration}

To confirm whether or not the intracellular $\mathrm{pH}$ changes with the addition of the citrate-containing buffer to the $E$. coli cell suspension, the intracellular $\mathrm{pH}$ of $E$. coli was determined using the fluorescent $\mathrm{pH}$ indicator dye SNARF-5F 5-(and-6)-carboxylic acid, acetoxymethyl ester, acetate (SNARF-5F-AM ester; Molecular Probes, OR, USA), basically in accordance with the manufacturer's protocol.

The solution of SNARF-5F-AM ester diluted with dimethyl sulfoxide (DMSO) was added to one milliliter of the $E$. coli cell suspension to give a final concentration of $10 \mu \mathrm{M}$. The mixture was then incubated at room temperature for $3 \mathrm{~h}$ with shading. After incubation with the SNARF-5F-AM, E. coli cells were washed twice and resuspended with $50 \mathrm{mM} \mathrm{Na} 2 \mathrm{HPO}_{4}-\mathrm{NaH}_{2} \mathrm{PO}_{4}$ buffer ( $\mathrm{pH} 7.0)$.

The SNARF-5F signals were calibrated by the high- $\mathrm{K}^{+} /$ nigericin method [31]. The ionophore nigericin (Molecular Probes) is generally used for intracellular $\mathrm{pH}$ calibration in the presence of $100-150 \mathrm{mM} \mathrm{K}{ }^{+}$to equilibrate the intracellular $\mathrm{pH}$ with the controlled extracellular $\mathrm{pH}$. As calibration solutions, a series of $50 \mathrm{mM} \mathrm{Na} 2 \mathrm{HPO}_{4}-\mathrm{NaH}_{2} \mathrm{PO}_{4}$ buffers containing $10 \mu \mathrm{g} /$ $\mathrm{ml}$ nigericin and $150 \mathrm{mM} \mathrm{KCl}$ with $\mathrm{pHs}$ ranging from 6.0 to 8.0 were prepared. For intracellular $\mathrm{pH}$ calibration, $50 \mu \mathrm{l}$ of the suspension of SNARF-5F-loaded E. coli cells and $950 \mu \mathrm{l}$ of $50 \mathrm{mM}$ $\mathrm{Na}_{2} \mathrm{HPO}_{4}-\mathrm{NaH}_{2} \mathrm{PO}_{4}$ buffers containing $10 \mu \mathrm{g} / \mathrm{ml}$ nigericin and 
$150 \mathrm{mM} \mathrm{KCl}$ were mixed and incubated at $25^{\circ} \mathrm{C}$ for $10 \mathrm{~min}$. After the incubation, the fluorescence spectra (emission at $630 \mathrm{~nm}$ ) of SNARF-5F loaded in the cells were measured using a fluorescence spectrometer.

\section{Supporting Information}

Table S1 Primers used for generation of cpFP-based indicators for citrate.

(DOCX)

Table S2 Metal ion sensitivity of GF98. (DOCX)

Figure S1 pH sensitivity of CF98. The fluorescence intensities (excitation at $504 \mathrm{~nm}$ and emission at $525 \mathrm{~nm}$ ) of CF98 were measured using a series of buffers prepared with $\mathrm{pHs}$ ranging from 6.5 to 8.0 containing the indicated citrate concentrations. $\mathrm{CF} 98$ is sensitive to $\mathrm{pH}$, but the magnitude relationship between fluorescence intensity and citrate concentration is maintained.

(TIF)

Figure S2 Effects of $\mathbf{p H}$ on the excitation spectra from aliquots of the cell suspension of SNARF-5F-loaded $E$. coli BL21(DE3)/pEGF98+pRCITT. The solid lines represent the excitation spectra of SNARF-5F from the cell suspensions diluted with calibration solutions for each of the indicated values of

\section{References}

1. Krebs HA (1940) The citric acid cycle: A reply to the criticisms of F. L. Breusch and of J. Thomas. Biochem J 34: 460-463.

2. Kirimura K, Honda Y, Hattori T (2011) Citric acid. In: Moo-Young M, editor. Comprehensive Biotechnology. Second Edition: Elsevier. pp. 135-142.

3. Demain AL, Sanchez S (2011) Microbial synthesis of primary metabolites: current trends and future prospects. In: El-Mansi EMT, Bryce CFA, Dahhou B, Sanchez S, Demain AL, et al., editors. Fermentation Microbiology and Biotechnology. Third Edition: CRC Press. pp. 77-100.

4. Geelen MJ, Schmitz MG (1993) The role of citrate in the regulation of hepatic fatty acid synthesis by insulin and glucagon. Horm Metab Res 25: 525-527.

5. Tosukhowong $\mathrm{P}$, Borvonpadungkitti S, Prasongwatana V, Tungsanga K, Jutuporn S, et al. (2002) Urinary citrate excretion in patients with renal stone: roles of leucocyte ATP citrate lyase activity and potassium salts therapy. Clin Chim Acta 325: 71-78.

6. Fricke ST, Rodriguez O, Vanmeter J, Dettin LE, Casimiro M, et al. (2006) In vivo magnetic resonance volumetric and spectroscopic analysis of mouse prostate cancer models. Prostate 66: 708-717.

7. Newman RH, Fosbrink MD, Zhang J (2011) Genetically encodable fluorescent biosensors for tracking signaling dynamics in living cells. Chem Rev 111: 3614 3666.

8. Kirimura K, Ogawa S, Hattori T, Kino K (2006) Expression analysis of alternative oxidase gene $(a \circ x)$ with enhanced green fluorescent protein as marker in citric acid-producing Aspergillus niger. J Biosci Bioeng 102: 210-214.

9. Hattori T, Honda Y, Kino K, Kirimura K (2008) Expression of alternative oxidase gene (aoxl) at the stage of single-cell conidium in citric acid-producing Aspergillus niger. J Biosci Bioeng 105: 55-57.

10. Honda Y, Kobayashi K, Kirimura K (2011) Increases in gene-targeting frequencies due to disruption of $k u e A$ as a $k u 80$ homolog in citric acid-producing Aspergillus niger. Biosci Biotechnol Biochem 75: 1594-1596.

11. Bermejo C, Ewald JC, Lanquar V, Jones AM, Frommer WB (2011) In VIVO biochemistry: quantifying ion and metabolite levels in individual cells or cultures of yeast. Biochem J 438: 1-10.

12. Evellin S, Mongillo M, Terrin A, Lissandron V, Zaccolo M (2004) Measuring dynamic changes in cAMP using fluorescence resonance energy transfer. Methods Mol Biol 284: 259-270.

13. Imamura H, Nhat KP, Togawa H, Saito K, Iino R, et al. (2009) Visualization of ATP levels inside single living cells with fluorescence resonance energy transferbased genetically encoded indicators. Proc Natl Acad Sci USA 106: 1565115656.

14. Dulla C, Tani H, Okumoto S, Frommer WB, Reimer RJ, et al. (2008) Imaging of glutamate in brain slices using FRET sensors. J Neurosci Methods 168: 306319.

15. Fehr M, Frommer WB, Lalonde S (2002) Visualization of maltose uptake in living yeast cells by fluorescent nanosensors. Proc Natl Acad Sci USA 99: 9846 9851 .
$\mathrm{pH}$. The dotted lines represent the excitation spectra of SNARF$5 \mathrm{~F}$ from the cell suspensions measured at $50 \mathrm{~s}$ after addition of the citrate-containing buffer to give the final concentration of $2.5 \mathrm{mM}$. Emission at $630 \mathrm{~nm}$.

(TIF)

Figure S3 Galibration curve of intracellular $\mathrm{pH}$ versus fluorescence intensity of SNARF-5F-loaded $E$. coli cells. The $\mathrm{pH}$ calibration curve constructed by plotting fluorescence intensities (excitation at $577 \mathrm{~nm}$ and emission at $630 \mathrm{~nm}$ ) of SNARF-5F from aliquots of the cell suspension of SNARF-5Floaded E. coli BL21(DE3)/pECF98+pRCITT diluted with each $\mathrm{pH}$ calibration solution against $\mathrm{pH}$.

(TIF)

Figure S4 The full nucleotide and protein sequences of CF98.

(TIFF)

\section{Acknowledgments}

We are grateful to Dr. Masanori Suzuki for critical comments on the manuscripts.

\section{Author Contributions}

Conceived and designed the experiments: YH KK. Wrote the paper: YH KK.

16. Fehr M, Lalonde S, Ehrhardt DW, Frommer WB (2004) Live imaging of glucose homeostasis in nuclei of COS-7 cells. J Fluoresc 14: 603-609.

17. Ewald JC, Reich S, Baumann S, Frommer WB, Zamboni N (2011) Engineering genetically encoded nanosensors for real-time in vivo measurements of citrate concentrations. PLoS One 6: e28245.

18. Baird GS, Zacharias DA, Tsien RY (1999) Circular permutation and receptor insertion within green fluorescent proteins. Proc Natl Acad Sci USA 96: 1124111246.

19. Nagai T, Sawano A, Park ES, Mivawaki A (2001) Circularly permuted green fluorescent proteins engineered to sense $\mathrm{Ca}^{2+}$. Proc Natl Acad Sci USA 98: 3197-3202.

20. Belousov VV, Fradkov AF, Lukyanov KA, Staroverov DB, Shakhbazov KS, et al. (2006) Genetically encoded fluorescent indicator for intracellular hydrogen peroxide. Nat Methods 3: 281-286.

21. Markvicheva KN, Bilan DS, Mishina NM, Gorokhovatsky AY, Vinokurov LM, et al. (2011) A genetically encoded sensor for $\mathrm{H}_{2} \mathrm{O}_{2}$ with expanded dynamic range. Bioorg Med Chem 19: 1079-1084.

22. Berg J, Hung YP, Yellen G (2009) A genetically encoded fluorescent reporter of ATP:ADP ratio. Nat Methods 6: 161-166.

23. Bott M, Meyer M, Dimroth P (1995) Regulation of anaerobic citrate metabolism in Klebsiella pneumoniae. Mol Microbiol 18: 533-546.

24. Bott M (1997) Anaerobic citrate metabolism and its regulation in enterobacteria. Arch Microbiol 167: 78-88.

25. Kaspar S, Perozzo R, Reinelt S, Meyer M, Pfister K, et al. (1999) The periplasmic domain of the histidine autokinase CitA functions as a highly specific citrate receptor. Mol Microbiol 33: 858-872.

26. Gerharz T, Reinelt S, Kaspar S, Scapozza L, Bott M (2003) Identification of basic amino acid residues important for citrate binding by the periplasmic receptor domain of the sensor kinase CitA. Biochem 42: 5917-5924.

27. Reinelt S, Hofmann E, Gerharz T, Bott M, Madden DR (2003) The structure of the periplasmic ligand-binding domain of the sensor kinase CitA reveals the first extracellular PAS domain. J Biol Chem 278: 39189-39196.

28. Sevvana M, Vijayan V, Zweckstetter M, Reinelt S, Madden DR, et al. (2008) A ligand-induced switch in the periplasmic domain of sensor histidine kinase CitA. J Mol Biol 377: 512-523.

29. McNicholas S, Potterton E, Wilson KS, Noble ME (2011) Presenting your structures: the CCP4mg molecular-graphics software. Acta Crystallogr D Biol Crystallogr 67: 386-394.

30. Pos KM, Dimroth P, Bott M (1998) The Escherichia coli citrate carrier CitT: a member of a novel eubacterial transporter family related to the 2-oxoglutarate/ malate translocator from spinach chloroplasts. J Bacteriol 180: 4160-4165.

31. Thomas JA, Buchsbaum RN, Zimniak A, Racker E (1979) Intracellular pH measurements in Ehrlich ascites tumor cells utilizing spectroscopic probes generated in situ. Biochem 18: 2210-2218.

32. Albe KR, Butler MH, Wright BE (1990) Cellular concentrations of enzymes and their substrates. J Theor Biol 143: 163-195. 
33. Bennett BD, Kimball EH, Gao M, Osterhout R, Van Dien SJ, et al. (2009) Absolute metabolite concentrations and implied enzyme active site occupancy in Escherichia coli. Nat Chem Biol 5: 593-599.

34. Lagunas R, Gancedo C (1983) Role of phosphate in the regulation of the Pasteur effect in Saccharomyces cerevisiae. Eur J Biochem 137: 479-483.

35. Gnoni GV, Priore P, Geelen MJ, Siculella L (2009) The mitochondrial citrate carrier: metabolic role and regulation of its activity and expression. IUBMB Life 61: $987-994$.
36. Chiu W, Niwa Y, Zeng W, Hirano T, Kobayashi H, et al. (1996) Engineered GFP as a vital reporter in plants. Curr Biol 6: 325-330.

37. Maruyama J, Nakajima H, Kitamoto K (2001) Visualization of nuclei in Aspergillus oryzae with EGFP and analysis of the number of nuclei in each conidium by FACS. Biosci Biotech Biochem 65: 1504-1510.

38. Nagai T, Ibata K, Park ES, Kubota M, Mikoshiba K, et al. (2002) A variant of yellow fluorescent protein with fast and efficient maturation for cell-biological applications. Nat Biotech 20: 87-90. 